\title{
Analysis of the Evolution of E-Business in the Channel Enhancement Stage in Retail Companies in Indonesia (Case study at PT Indomarco Prismatama (Indomaret)
}

\author{
Analisis Evolusi E-Business Tahap Channel Enhancement pada \\ Perusahaan Retail di Indonesia \\ (Studi kasus pada PT Indomarco Prismatama (Indomaret)
}

\author{
Elsa Zulfita 1); Deby Nofriansyah 2); Indah Wulan Sari Batubara 2) ; Nurbaiti 2) \\ 1,2) Jurusan Manajemen, Fakultas Ekonomi dan Bisnis Islam, Universitas Islam Negeri Sumatera Utara \\ Email: ${ }^{1)}$ elsazulfita93@gmail.com ; ${ }^{2)}$ debynofriansyah171101@gmail.com; ${ }^{2)}$ indahbatubara17@gmail.com; \\ 2) nurbaiti@uinsu.ac.id
}

How to Cite:

Zulfita, E., Nofriansyah, D., Batubara, I. W. S., Nurbaiti. (2022). Analysis of the Evolution of E-Business in the Channel Enhancement Stage in Retail Companies in Indonesia (Case study at PT Indomarco Prismatama (Indomaret)). Jurnal Ekonomi Manajemen Akuntansi Dan Keuangan, 3(1). DOI: https://doi.org/10.53697/emak.v3i1

ARTICLE HISTORY

Received [22 Desember 2021]

Revised [29 Desember 2021]

Accepted [05 Januari 2022]

\section{KEYWORDS}

E-Business Evolution, Channel Enhancement, Indomaret.

This is an open access article under the CC-BY-SA license

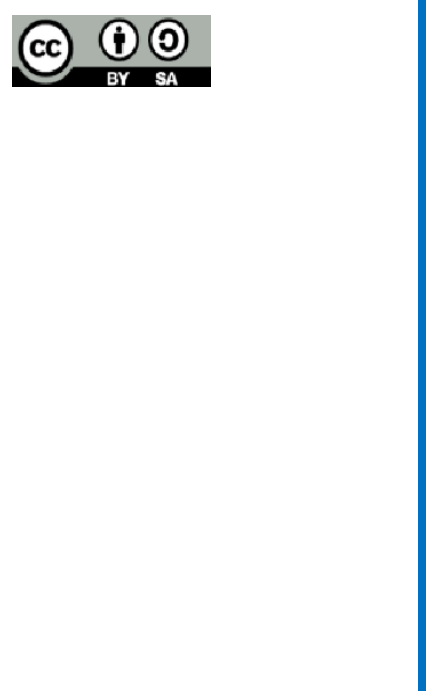

\section{ABSTRAK}

Penelitian ini bertujuan untuk mengetahui bagaimana evolusi ebusiness tahap Channel Enhancement terjadi pada salah satu perusahaan retail terbesar di Indonesia. Sampel penelitian ini adalah PT Indomarco Prismatama (Indomaret). Dalam penelitian ini, menggunakan metode studi kasus dengan pendekatan kualitatif. Teknik pengumpulan data dilakukan dengan menggunakan studi literatur, observasi dan studi dokumentasi. Hasil dari penelitian ini menunjukkan bahwa perusahaan PT Indomarco Prismatama atau Indomaret telah memanfaatkan perkembangan teknologi informasi dengan optimal dengan mengimpelementasikannya ke dalam sebuah website dan aplikasi digital. Sehinga dengan ini peerusahaan tersebut telah memasuki dan menerapkan tahap evolusi Channel Enhancement tersebut dengan sangat maksimal.

\section{ABSTRACT}

This study aims to find out how the evolution of e-business in the Channel Enhancement stage occurred in one of the largest retail companies in Indonesia. The sample of this research is PT Indomarco Prismatama (Indomaret). In this study, using a case study method with a qualitative approach. Data collection techniques were carried out using literature studies, observation and documentation studies. The results of this study indicate that the company PT Indomarco Prismatama or Indomaret has optimally utilized the development of information technology by implementing it into a website and digital application. Thus, the company has entered and implemented the Channel Enhancement evolution stage to the maximum extent.

\section{PENDAHULUAN}

Perkembangan dunia bisnis saat ini sudah semakin pesat. Hal ini mendorong perusahaan untuk dapat mengubah atau bertransformasi bahkan berevolusi untuk dapat bertahan di tengah

156 | Elsa Zulfita, Deby Nofriansyah, Indah Wulan Sari Batubara, Nurbaiti; Analysis of the Evolution... 
ketatnya persaingan bisnis yang terjadi saat ini. Dewasa ini, berbagai perusahaan konvensional sudah bertransformasi dan berevolusi menjadi perusahaan yang "butuh" akan teknologi. Teknologi memang sudah menjadi kebutuhan penting dalam dunia yang serba elektronik seperti saat ini. Dengan adanya teknologi di dalam dunia bisnis saat ini, maka akan mempermudah proses operasional perusahaan baik dari segi pemasaran, ataupun dari segi transaksi dan penjualan produk. Proses pemanfaatan teknologi dalam bisnis inilah yang disebut dengan elektronik binis atau e-business.

Menurut Dhillon dan Kaur (2012) e-business adalah sebuah teknologi untuk mengembangkan bisnis baik internal seperti SDM, administrasi dan keuangan, dan proses eksternal seperti penjualan, penyediaan barang dan jasa serta hubungan konsumen. Di dalam perkembangan dunia e-binis yang sangat pesat saat ini, ada empat tahapan evolusi yang dapat menjadi bahan pijakan yaitu: (1) Channel Enhancement; (2) Value-Chain Integration; (3) Industry Transformation; dan (4) Convergence.

Pada penelitian ini, kami akan menganalisis mengenai tahapan evolusi e-bisnis yang pertama yaitu Channel Enhancement terhadap salah satu perusahaan retail terbesar yang ada di Indonesia yaitu PT Indomarco Prismatama atau dengan nama gerainya yang terkenal yaitu Indomaret. Penelitian ini bertujuan untuk mengetahui bagaimana perusahaan PT Indomarco Prismatama atau Indomaret tersebut berevolusi ke dalam tahap e-bisnis yang pertama yakni Channel Enhancement.

\section{LANDASAN TEORI}

\section{Evolusi E-Business}

Evolusi e-business di dalam dunia digital mempunyai makna yang tidak sama bagi setiap perusahaan, khususnya yang masih menerapkan konsep lama dalam berbisnis (konvensional). Banyak perusahaan yang berhati-hati dalam merespon fenomena tersebut dan terlalu cepat dalam mengambil tindakan terhadap berbagai kemudahan yang ditawarkan oleh internet. Jika dibandingan dengan negara-negara maju yang telah berani melakukan sebuah gerakan perubahan untuk secara keseluruhan mengganti metode mereka dalam berbisnis, dikarenakan bermacammacam alasan negara-negara berkembang seperti Indonesia memilih untuk menggunakan pendekatan evolusi. Tujuannya ialah tidak hanya agar supaya resiko yang akan ditanggung nantinya menjadi lebih kecil, perusahaan juga berniat untuk memastikan agar proses perubahan business konvensional ke arah e-business benar-benar dapat memberikan nilai dan manfaat bagi pelanggan. Terdapat empat tahapan evolusi yang bisa dilakukan sebagai bahan pijakan, yakni:

1. Channel Enhancement

2. Value-Chain Integration

3. Industry Transformation

4. Convergence

\section{Channel Enhancement}

Perusahaan yang masih menggunakan konsep konvensional dan memiliki keinginan untuk memanfaatkan internet dalam perusahaannya bisa memulai dengan mempergunakan teknologi informasi sebagai jaringan informasi atau alat penghubung yang dapat menghubungkan perusahaan dengan para konsumennya. Dengan memanfaatkan internet sebagai alat alternatif agar bisa terhubung dengan para mitra bisnis termasuk konsumen, untuk itu perusahaan tidak perlu merasa khawatir akan kehilangan pangsa pasar yang sudah dimiliki sekarang karena akses melalui internet hanya merupakan salah satu pilihan utama saja di mana sebagai pelengkap fasilitas konsep lama yang telah ada.

Apabila pada waktunya melihat dari evaluasi dan observasi yang telah dilakukan mulai nampak munculnya tren kemunduran pelanggan yang lebih memilih internet dibandingkan cara 
konvensional, maka disaat itulah cara yang lama ini akan mulai dapat ditinggalkan dan digantikan oleh internet. Dengan melakukan tahap Channel Enhancement ini, sebuah perusahaan sudah bisa dikatakan dapat menerapkan dan mengaplikasikan yang disebut dengan e-business pada tahap awal.

\section{Sejarah Indomaret (PT Indomarco Prismatama)}

Pada mulanya, minimarket Indomaret adalah sebuah rancanga yang berkonsep gerai yang dilokasikan dekat dengan pemukiman masyarajat. Gerai yang bernama Indomaret ini menyediakan berbagai keperluan masyarakat mulai dari kebutuhan pokok, makanan ringan dan sereal, serta beragam jenis lainnya. Seiring berjalannya waktu dengan mengikuti apa yang menjadi tren dan kebutuhan masyarakat setiap tahunnya, Indomaret terus memperluas dan memperbanyak cabnagcabang gerainya di berbagai kawasan seperti kawasan perumahan, tempat wisata, kawasan niaga, bahkan juga kawasan daerah di dataran tinggi. Hal ini membuat Indomaret untuk terus menciptakan inovasi dan sebagai proses pembelajaran yang di mana menjadikan Indomaret sebagai suatu jaringan bisnid ritel berskala besar yang Irngkap dan beragam.

Pada tahun 1997, Indomaret memulai mengembangkan bisnisnya dengan menggunakan sistem waralaba. Dengan menggunakan sistem tersebut, Indomaret bisa menyediakan peluang untuk masyarakat umum agar bisa bekerjasama dan memperoleh pendapatan. Konsep bisnis waralaba Indomaret diakui menjadi pelopor dan pertama dalam bidang retail di Indonesia. Bahkan, respon masyarakat terhadap bisnis waralaba Indomaret ini bisa dikatakan sangat baik dan posotif. Hal ini dapat dilihat dengan semakin banyaknya mitra dari Indomaret dari tahun ke tahun. Konsep bisnis waralaba dari Indomaret ini juga mendapat pengakuan dari Pemerintah Indonesia dan bahkan Indomaret pun diganjar dengan penghargaan dengan predikat "Perusahaan Waralaba Unggul Tahun 2003". Penghargaan ini merupakan yang pertama diberikan kepada perusahaan minimarket di Indonesia. Bahkan sampai sekarang ini, Indomaret satu-satunya perusahaan retail yang memperoleh penghargaan tersebut.

Pada awal tahun 2011, Indomaret mengganti logo lamanya dengan logo baru yang digunakan sampai saat ini yang mana logo tersebut berwarna biru, merah, dan kuning. Di masa sekarang, minimarket Indomaret berkembang dengan pesat. Jumlah gerainya pun telah mencapai 16.000, terdiri dari 40\% gerai milik mitra waralaba serta 60\% gerai milik PT Indomarco Prismatama. Ada pula, sumber barang untuk seluruh gerai Indomaret mayoritas berasal dari 33 pusat distribusi milik PT Indomarco Prismatama. Pusat-pusat distribusi Indomaret ini menyediakan lebih dari 5.000 jenis produk. Selain itu, kehadiran bisnis waralaba Indomaret saat ini makin berkembang dengan adanya Indogrosir, yang mana ini adalah anak perusahaan dengan menggunakan konsep bisnis perkulakan.

\section{METODE PENELITIAN}

Metode penelitian yang digunakan ialah pendekatan kualitatif, yang mana pendekatan ini berisi pengolahan data seperti mereduksi, menyajikan lalu memverivikasi data tersebut di mana tidak mengguakan perhitungan-perhitungan di dalamnya. Metode penelitian yang akan digunakan adalah metode studi kasus yaitu sebuah metode yang bertujuan untuk mengungkapkan fakta sebenarnya di lapangan sebagai mana keadaan nyatanya, secara intensif, mendalam dan komprehensif.

Teknik pengumpulan data pada penelitian kali ini menggunakan berbagai alternatif dan teknik yang akan di obsevasi dari berbagai sumber yang ada. Di dalam penelitian ini, teknik pengambilan data dan informasi yang dipakai adalah studi literatur, observasi dan studi dokumentasi. Unit penelitian ini adalah PT Indomarco Prismatama atau Indomaret. Unit analisisnya adalah mengenai salah satu dari empat tahapan evolusi e-business yaitu Channel Enhancement.. 
HASIL DAN PEMBAHASAN

Berdasarkan analisa melalui observasi dan studi dokumentasi yang sudah dilakukan, maka hasil yang di dapat ialah sebagai berikut:

Tahap evolusi Channel Enhancement

1. Perusahaan retail Indomaret tersebut sudah mencapai tahap evolusi ini karena perusahaan tersebut sudah mulai memanfaatkan internet dan teknologi yang mana sudah terimplementasikan dalam sebuah website bernama www.indomaret.co.id yang bisa dilihat pada gambar di bawah ini

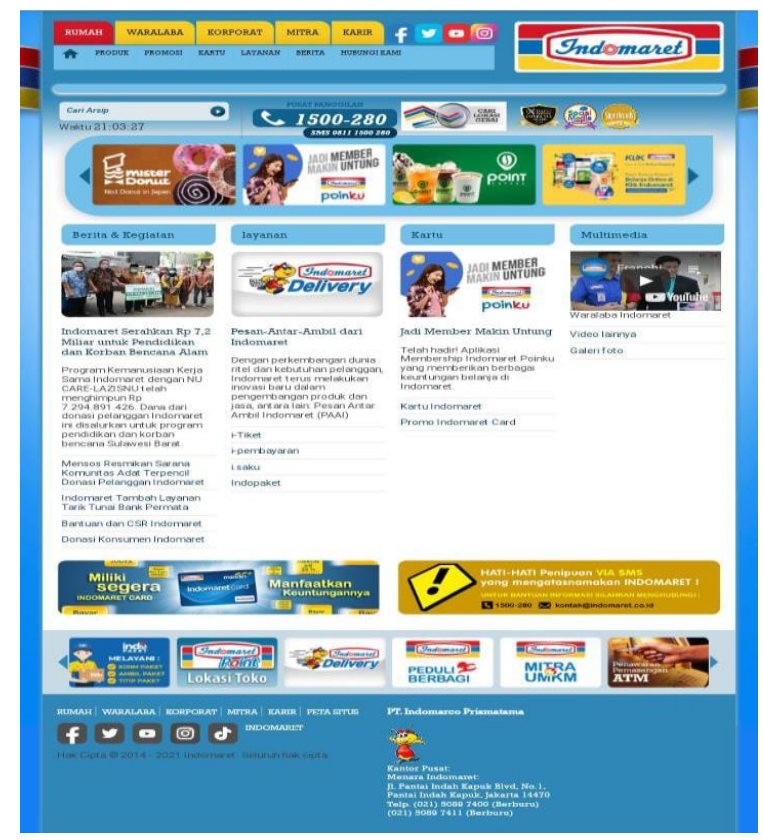

Gambar 1. Evolusi Perusahaan Indomarco Prismatama (Indomaret)

Sumber: Internet

Gambar 1. diatas adalah salah satu bentuk evolusi Perusahaan Indomarco Prismatama (Indomaret) yang mana perusahaan tersebut sudah memiliki website resmi yang memiliki cukup banyak fitur seperti Berita dan Kegiatan, Layanan, Kartu Member, Multimedia, Karir dan Waralaba.

Pada fitur Berita dan Kegiatan berisi kegiatan-kegiatan yang dilakukan oleh perusahaan tersebut misalnya yang terlihat pada gambar di bawah ini

Berita \& Kegiatan
Indomaret Serahkan Rp 7,2 Miliar untuk
Pendidikan dan Korban Bencana Alam
Program kemanusiaan kerja sama Indomaret dengan
NU CARE-LAZISNU telah menghimpun Rp
7.294.891.426. Dana dari donasi pelanggan
Indomaret ini disalurkan untuk program pendidikan
dan korban bencana Sulawesi Barat.
Mensos Resmikan Sarana Komunitas Adat Terpencil
Donasi Pelanggan Indomaret
Indomaret Tambah Layanan Tarik Tunai Bank Permata
Bantuan dan CSR Indomaret
Donasi Konsumen Indomaret

Gambar 2. Fitur Berita dan Kegiatan

Sumber: Internet 
Pada fitur Layanan terdapat pula layanan Pesan Antar Ambil Indomaret (PAAl) yang mana fitur ini adalah salah satu inovasi mereka dalam pengembangan produk dan jasa di era yang serba online seperti ini. Perusahaan ini juga menyediakan fitur pembayaran secara digital seperti iPayment dan i.saku untuk memudahkan konsumen dalam melakukan transaksi secara daring/online. Indomaret bahkan juga menyediakan fitur i-Tiket untuk pemesanan tiket transportasi, event-event seperti konser dan sejenisnya serta tiket untuk wahana rekreasi secara online seperti yang terlihat pada gambar di bawah ini.

Layanan
Pesan-Antar-Ambil dari Indomaret
Sejalan dengan perkembangan dunia ritel dan
kebutuhan pelanggan, Indomaret terus melakukan
inovasi baru dalam pengembangan produk dan jasa,
antara lain: Pesan Antar Ambil Indomaret (PAAI)
i-Tiket
i-Payment
i.saku
Indopaket

Gambar 3. Fitur layanan

Sumber: Internet

Pada fitur Kartu ini Perusahaan Indomarco Prismatama menyediakan kartu yang memudahkan para member Indomaret untuk melakukan berbagai pembayaran dengan diskon langsung seperti pembayaran toll, bus Trans, Kereta KRL, dan lain sebagainya seperti yang terlihat pada gambar di bawah ini.

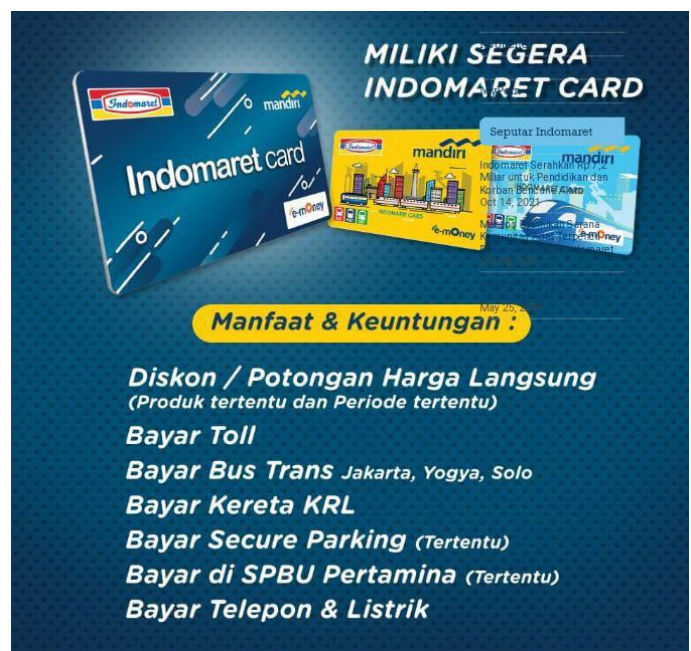

Gambar 4. fitur Kartu Perusahaan Indomarco Prismatama Sumber: Internet

Selain membuat website resmi, PT Indomarco Prismatama ini juga membuat sebuah aplikasi pemesanan berbagai macam produk mulai dari elektronik, kecantikan dan kesehatan, produk Ibu dan bayi dan lain sebagainya yang membuat aplikasi ini hampir setara dengan aplikasi e-commerce lainnya secara online yang bernama Klik Indomaret. 


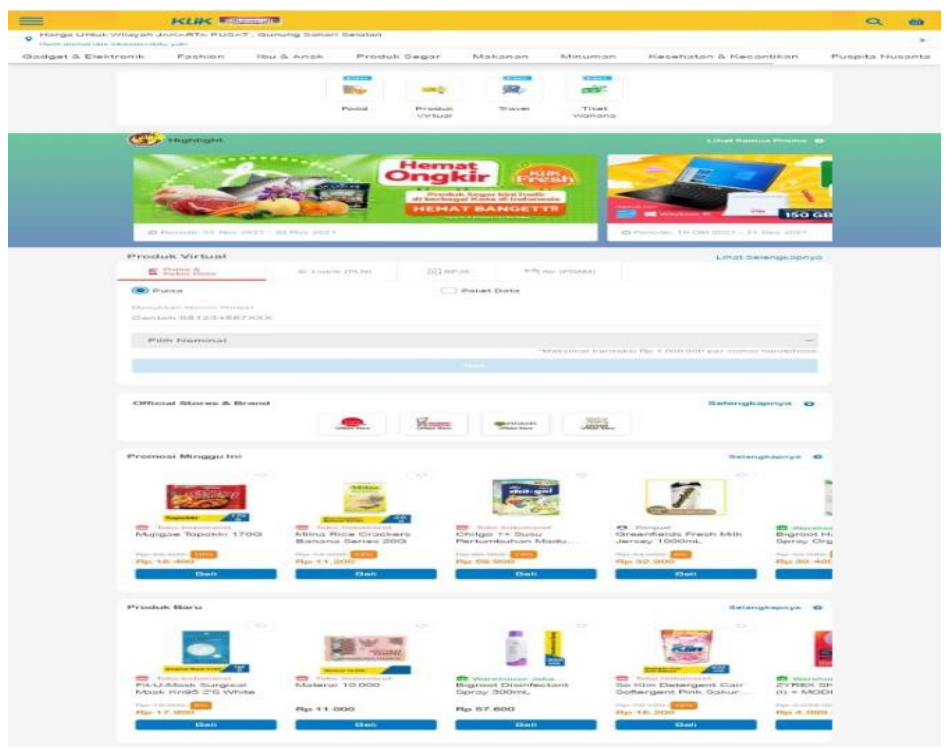

Gambar 5. Klik Indomaret

Sumber: Internet

Dapat dilihat bahwa aplikasi Klik Indomaret ini begitu lengkap, tidak hanya menyediakan produk-produk lokal Indomaret saja, melainkan juga menyediakan produk-produk luar seperti gadget dan elektronik, produk perlengkapan rumah tangga, produk kecantikan dan kesehatan serta produk fashion. Tidak hanya itu, aplikasi ini juga menyediakan pembelian dan pembayaran pulsa, token listrik, paket data internet dan wifi, BPJS serta pembayaran air (PDAM).

Jadi, berdasarkan analisis mengenai evolusi e-business pada tahap Channel Enhancement terhadap PT Indomarco Prismatama ini sudah sangat maksimal sekali. Perusahaan ini benar-benar secara maksimal memanfaatkan perkembangan teknlogi yang ada dan menerapkannya pada bisnis retail mereka yang mana membuat perusahaan ini menjadi salah satu perusahaan retail terbesar di Indonesia. Melalui perkembangan yang begitu pesat dengan hadirnya website serta aplikasi yang mumpuni nan lengkap, perusahaan ini sudah berevolusi secara optimal ke dalam elektronik business yang sebenarnya.

\section{KESIMPULAN DAN SARAN}

Hasil obsevasi dan analisis yang sudah dilakukan, untuk itu dapat disimpulkan bahwa PT Indomarco Prismatama atau Indomaret telah mencapai tahap evolusi e-business yang pertama yaitu Channel Enhancement dengan memanfaatkan teknlogi secara optimal dan mengimplementasikannya dalam bentuk sebuah website serta aplikasi yang bisa digunakan untuk dapat memudahkan proses pembelian barang serta dalam proses transaksi dan pengiriman. Penelitian ini hanya terbatas pada tahap evolusi yang pertama saja sehingga saran untuk peneliti berikutnya agar dapat menganalisis tahapan-tahapan evolusi yang lainnya dengan lebih cermat dari peneliti sebelumnya.

\section{DAFTAR PUSTAKA}

Firdaus, Rangga (2020).Buku Pegangan Dosesn: E-Business. Jakarta.

Hifzhan, Achmad \& Sunarti. (2015). Upaya Pengembangan E-Business dalam Pemasaran Produk Secara Internasional. Jurnal Administrasi Bisnis, 23 (1), 1-8.

Subekti, Mohammed. (2014). Pengembangan Model E-Business di Indonesia. Jurnal Comtech, 5 (2), 925-938. 
Dhillon, Rashem dan Sukhpreet Kaur. (2012). Review Paper on e-Business \& CRM. www.researchmanuscripts.com/isociety2012/64.pdf. (Diakses tanggal 9 November 2021)

Perkasa, Muhammad. (2019). Mengenal Sejarah Indomaret, Pelopor Bisnis Minimarket di Indonesia. https://marketeers.com/mengenal-sejarah-indomaret-pelopor-bisnis-minimarket-diindonesia/. (Diakses tanggal 10 November 2021)

162 | Elsa Zulfita, Deby Nofriansyah, Indah Wulan Sari Batubara, Nurbaiti; Analysis of the Evolution... 